\title{
Investigation on the bandgap of semiconductor solid solution $\mathrm{Hg}_{1-\mathrm{x}-\mathrm{y}-\mathrm{z}} \mathrm{Cd}_{\mathrm{x}} \mathrm{Mn}_{\mathrm{y}} \mathrm{Zn}_{\mathrm{z}} \mathrm{Te}$
}

\author{
V.V. Zhikharevich, S.E. Ostapov, V.G. Deibuk \\ Chernivtsi National University, 2, Kotsyubinsky str., 58012 Chernivtsi, Ukraine
}

\begin{abstract}
The paper presents a investigation on the bandgap of a new narrow-gap semiconductor solid solution $\mathrm{Hg}_{1-\mathrm{x}-\mathrm{y}-\mathrm{z}} \mathrm{Cd}_{\mathrm{x}} \mathrm{Mn}_{\mathrm{y}} \mathrm{Zn}_{\mathrm{z}}$ Te via optical measurements. Modeling of the edge of fundamental absorption for $\mathrm{Hg}_{1-\mathrm{x}-\mathrm{y}-\mathrm{z}} \mathrm{Cd}_{\mathrm{x}} \mathrm{Mn}_{\mathrm{y}} \mathrm{Zn}_{\mathrm{z}} \mathrm{Te}$ is performed and specifying values of the bandgap at room temperature in crystals under study are determined.
\end{abstract}

Keywords: bandgap, band structure, solid solutions.

Manuscript received 10.02.06; accepted for publication 23.10.06.

\section{Introduction}

Multicomponent semiconductor solid solutions have long been the object of attention of investigators, since they can serve as alternative materials to $\mathrm{Hg}_{1-\mathrm{x}} \mathrm{Cd}_{\mathrm{x}} \mathrm{Te}$ for creation of IR photodetectors in the ranges of 3 to 5 and 8 to $14 \mu \mathrm{m}$. As compared to $\mathrm{Hg}_{1-\mathrm{x}} \mathrm{Cd}_{\mathrm{x}} \mathrm{Te}$, these materials offer essential advantages due to the presence of an additional component - manganese or zinc. It is known [1] that the presence of lower size atoms in crystal lattice can contribute to relaxation of elastic deformations and improvement of structural perfection of crystals. Owing to a smaller ion radius as compared to cadmium (see Table 1), Mn and $\mathrm{Zn}$ can cause precisely this effect on the crystal structure of multicomponent solid solutions based on $\mathrm{Hg}_{1-\mathrm{x}} \mathrm{Cd}_{\mathrm{x}} \mathrm{Te}$.

As is evident from the Table, the atoms of manganese and zinc are essentially different from the atoms of cadmium both in the ionic and atomic radii. The differences in the electron structure of outer electron shells are considerable as well.

All these factors taken together contribute to the difference in macroscopic properties of solid solutions comprising the above elements as compared to $\mathrm{Hg}_{1-\mathrm{x}} \mathrm{Cd}_{\mathrm{x}} \mathrm{Te}$. In particular, strengthening of atomic bonds in crystals, comprising $\mathrm{Zn}$, is testified by reduced lattice parameter $(6.1037 \AA$ in ZnTe against $6.482 \AA$ in $\mathrm{CdTe})$. This is also confirmed by the increased melting point $\left(1290{ }^{\circ} \mathrm{C}\right.$ in $\mathrm{ZnTe}$ as compared with $1092{ }^{\circ} \mathrm{C}$ in $\mathrm{CdTe}$ ), as well as by increased mercury diffusivity when annealing $\mathrm{HgZnTe}$ crystals as compared to $\mathrm{Hg}_{1-\mathrm{x}} \mathrm{Cd}_{\mathrm{x}} \mathrm{Te}$ [3].

As regards solid solutions comprising $\mathrm{Mn}$, their parameters (MnTe melting point $1167^{\circ} \mathrm{C}$ [4] and lattice parameter $6.345 \AA[5,6])$ do not quite agree with this reasoning. However, in our view, this is related to a change from cubic to hexagonal crystal structure $\mathrm{Mn}_{\mathrm{x}} \mathrm{Hg}_{1-\mathrm{x}} \mathrm{Te}$ at $x>0.3$.

In Refs [7,8], it is shown that addition of manganese ions to solid solution $\mathrm{Hg}_{1-\mathrm{x}} \mathrm{Cd}_{\mathrm{x}} \mathrm{Te}$ makes possible a more precise bandgap control, as well as causes a change in the effective mass, parameters of impurity states. This effect is attributable to interaction between the spins of free electrons and localized magnetic moments of $3 d$-electrons.

Obviously, the presence of manganese as a magnetic component adds certain difficulties, for example, by formation of antiferromagnetic clusters [9, 10] or spin-glass transition at low temperatures. However, there is an evidence that the presence of manganese also contributes to processes of crystal structure relaxation, reduction of fluctuations in the solid solution composition and its homogeneity increase. These changes were observed by spectrometric methods and galvanomagnetic measurements [11, 12]. Experimental proof was also obtained by observation of unusually narrow and bright photoluminescence peak in $\mathrm{Hg}_{1-\mathrm{x}-\mathrm{y}} \mathrm{Cd}_{\mathrm{x}} \mathrm{Mn}_{\mathrm{y}} \mathrm{Te}$ [13].

Thus, in our opinion, the reasons for considerable improvement of optical and kinetic characteristics of multicomponent solid solutions as compared to $\mathrm{Hg}_{1-\mathrm{x}} \mathrm{Cd}_{\mathrm{x}} \mathrm{Te}$ can be considered.

One of new multicomponent materials obtained recently is $\mathrm{Hg}_{1-\mathrm{x}-\mathrm{y}-\mathrm{z}} \mathrm{Cd}_{\mathrm{x}} \mathrm{Mn}_{\mathrm{y}} \mathrm{Zn}_{\mathrm{z}}$ Te [14-16]. The specific feature of this material lies in the fact that it simultaneously includes both manganese and zinc ions, which will possibly contribute to further improvement of its parameters as compared to $\mathrm{Hg}_{1-\mathrm{x}} \mathrm{Cd}_{\mathrm{x}} \mathrm{Te}$, in particular: a) greater stability; b) greater structural perfection; c) better surface and interface properties [14-16]. 
Despite good prospects of these materials, their basic parameters are not studied well. It primarily relates to the bandgap, precise knowledge of which is needed to calculate the basic parameters of various kinds of IR radiation photodetectors, such as photoresistors, photodiodes, Schottky diodes.

One of the most widespread methods for studying the bandgap $E_{g}$ is based on the measurement of interband absorption spectra. For direct-band semiconductors, including $\mathrm{Hg}_{1-\mathrm{x}-\mathrm{y}-\mathrm{z}} \mathrm{Cd}_{\mathrm{x}} \mathrm{Mn}_{\mathrm{y}} \mathrm{Zn}_{\mathrm{z}} \mathrm{Te}$, this method yields rather unambiguous result only at small thicknesses of samples $(d<10 \mu \mathrm{m})$, when interband absorption spectra correspond to a model of electron transition in a crystal with a regular lattice (Kane spectral region). In thick samples $(d>>10 \mu \mathrm{m})$ this area is inaccessible for observation, and the short-wave edge of absorption band has exponent form and obeys the Urbach rule:

$$
\alpha_{I B}=\alpha_{g} \exp \left(\frac{\hbar \omega-E_{g}}{W}\right),
$$

in so doing, dependence of $\alpha_{g}$ on $E_{g}$ is not precisely known.

In this case, there is some uncertainty in the results of measuring $E_{g}$ caused by the ambiguity of the preexponential factor $\alpha_{g}$ in the formula (1). To avoid the ambiguity, it is generally assumed that at room temperature $\alpha_{g} \approx 500 \mathrm{~cm}^{-1}$ [17]. However, this assumption has in fact no justification, so the validity of this approach is doubtful, and the error of measuring $E_{g}$ can make a value of order $W$ (several $\mathrm{meV})$, which is inadmissible.

The emergence of exponential tail of interband absorption is attributable to various reasons. In particular, it is often related to the occurrence of valence band and conduction band "tails" due to crystal field fluctuations in heavily doped compensated semiconductors and other disordered systems (such as solid solutions, amorphous or glass-like semiconductors) [18].

It is evident that the optimal solution of the problem to find $E_{g}$ from measurements of interband absorption spectra is to construct a model that would permit to calculate the value $\alpha_{g}$ in each particular case, having other crystal characteristics defined experimentally or theoretically by independent means [19].

This paper utilizes a model based on the assumption that smearing the absorption edge in $\mathrm{Hg}_{1-\mathrm{x}-\mathrm{y}-\mathrm{z}} \mathrm{Cd}_{\mathrm{x}} \mathrm{Mn}_{\mathrm{y}} \mathrm{Zn}_{\mathrm{z}} \mathrm{Te}$, like that in solution $\mathrm{Hg}_{1-\mathrm{x}} \mathrm{Cd}_{\mathrm{x}} \mathrm{Te}$, is determined by thermal expansion factor [19-20], as well as by joint effects of electron system interaction with composition fluctuations and a system of charged centers. In such a system, the law of energy conservation during electron transport in the process of photon absorption is of the form: $E_{f}-E_{i}=\hbar \omega+E$ [20], where $E_{f}, E_{i}$ are electron energies in the final and initial states, respectively; $E$ is the additional energy transferred to electron or taken from it by crystal lattice or impurities during transport. The $E$ value itself is considered here as random, and its sign can be both positive and negative. Under these conditions the probability of photon absorption should be determined by the convolution type of integral, including under its sign the probability of absorption in perfect crystal and certain weight function - the thermal expansion factor $\Gamma(E)$ determined by the law of distribution of random value $E$. Hence, in this case the problem is reduced to establishing the type of $\Gamma(E)$ factor. The essence of the model lies in the fact that true $\Gamma(E)$ factor is replaced by the trial one, so that the asymptotic form of absorption edge conforms to the experiment. Parameters of this trial factor are determined by comparison to experiment.

The expression for interband absorption coefficient in this case is of the form [20]:

$$
\begin{aligned}
& \alpha_{I B}=\frac{4 \pi^{2} e^{2} P^{2}}{6 \eta \eta_{0} \hbar c} \times \\
& \sum_{v} \int_{0}^{\infty}\left[1-\exp \left(-\frac{E+E_{g}}{k_{\mathrm{B}} T}\right)\right] \cdot \frac{\Gamma\left(\hbar \omega-E-E_{g}\right)}{E+E_{g}} N_{c}\left(\varepsilon_{v}^{\prime}\right) \times \\
& \times f\left(E_{v}-E+\varepsilon_{v}^{\prime}\right)\left[1-f\left(E_{c}+\varepsilon_{v}^{\prime}\right)\right] \times \\
& \times \frac{m_{v}\left[k_{c}\left(\varepsilon_{v}^{\prime}\right)\right]}{m_{v}\left[k_{c}\left(\varepsilon_{v}^{\prime}\right)\right]+m_{c}\left[k_{c}\left(\varepsilon_{v}^{\prime}\right)\right]} d E,
\end{aligned}
$$

where $\varepsilon_{j}(k)$ and $k_{j}(\varepsilon)$ are the direct and inverse dispersion laws, $m_{j}(k)$ is the effective mass of the density of states, $N_{j}(\varepsilon)$ is the density of states in the $j$-th band, $\varepsilon_{v}^{\prime}$ is the root of equation $\varepsilon+\varepsilon_{v}\left[k_{c}(\varepsilon)\right]=E$. The sum is taken over the branches of the valence band. The relationship (2) is valid with any kind of interaction in a crystal, provided formation of new states can be ignored.

Note that $\Gamma(E)$ enters (2) under the sign of integration and with a weak disordering has the form of a rather narrow peak with certain characteristic width $W \sim \hbar \omega_{\mathrm{LO}}$ [20]. Accordingly, the general appearance of absorption tail depends on the form of only that part of $\Gamma(E)$, where $E<-W$. The values of $\Gamma(E)$ in the other part of definition area affect the value of the factor $\alpha_{g}$ only indirectly. Therefore, to approximately calculate $\alpha_{g}$ instead of $\Gamma(E)$ one can use a simplified form of a model (trial) function suitable for this. Choosing this function, one can use such evident properties of $\Gamma(E)$ as smoothness and continuity, normalization for unity and evenness (at least, at sufficiently high temperatures, when thermal disordering prevails and the probabilities of electron transport with phonon absorption and radiation are close) [20]. Besides, consideration must be given to the fact that to agree with the experiment, the asymptote $\Gamma(E)$ at $E<-W$ should look as $\exp (-|E / W|)$ for crystals with exponential shape of absorption band edge.

As a model function that meets all the above conditions one can propose, for example, the following function [19]: 


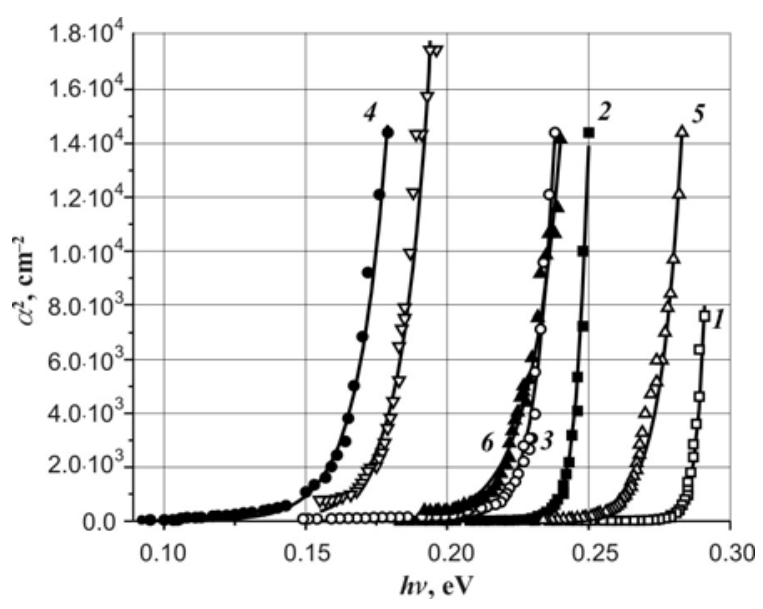

Fig. 1. Experimental and calculated absorption spectra of the samples $\mathrm{Hg}_{1-\mathrm{x}-\mathrm{y}-\mathrm{z}} \mathrm{Cd}_{\mathrm{x}} \mathrm{Mn}_{\mathrm{y}} \mathrm{Zn}_{\mathrm{z}} \mathrm{Te}$ with preloading composition: $x=0.14 ; y=0.02 ; z=0.01$.

$$
\begin{aligned}
& \Gamma(E)=\frac{g(z)}{2 W}\left(1+\frac{z}{2}-\frac{E^{2}}{2 z W^{2}}\right) \exp (-z), \text { when }|E| \leq z W \mid \\
& \Gamma(E)=\frac{g(z)}{2 W} \exp \left(-\frac{|E|}{W}\right), \text { when }|E| \geq z W
\end{aligned}
$$

where $g(z)=\left(1+z+z^{2 / 3}\right)^{-1} \exp (z), z$ is the parameter that defines the starting point when the dependence $\Gamma(E)$ becomes exponential.

The function (3) decays to zero by the exponential law at $|E|>z$, and at $|E|<z$ it has the form of the inverse parabola. Coefficients in (3) are selected under condition of smoothness and continuity of $\Gamma(E)$, and $g(z)-$ under condition of normalization.

To define parameter $z$ and check the basic model regulations, the absorption spectra of IR radiation by crystals $\mathrm{Hg}_{1-\mathrm{x}-\mathrm{y}-\mathrm{z}} \mathrm{Cd}_{\mathrm{x}} \mathrm{Mn}_{\mathrm{y}} \mathrm{Zn}_{\mathrm{z}}$ Te of various compositions

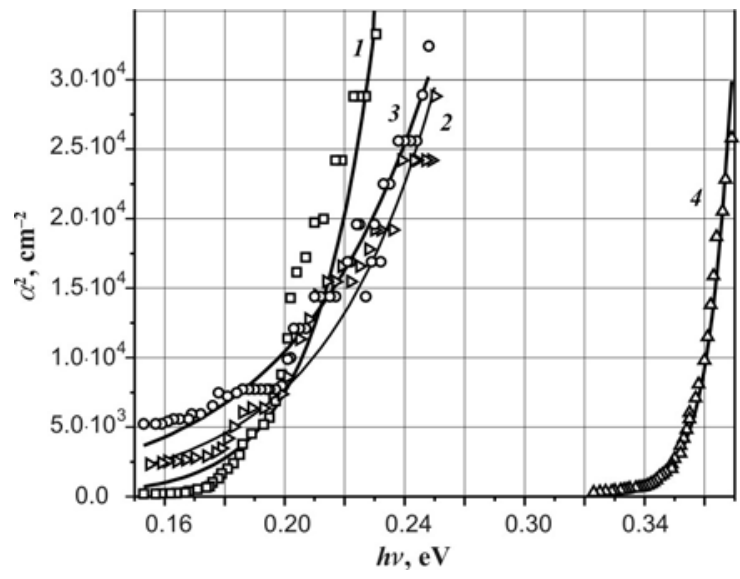

Fig. 2. The comparison of the experimental and calculated absorption spectra of the samples $\mathrm{Hg}_{1-\mathrm{x}-\mathrm{y}-\mathrm{z}} \mathrm{Cd}_{\mathrm{x}} \mathrm{Mn}_{\mathrm{y}} \mathrm{Zn}_{\mathrm{z}} \mathrm{Te}$ with preloading composition: $x=0.1 ; y=0.04 ; z=0.01$. and impurity concentrations at room temperature were studied. The results of experimental and theoretical investigations are given in Figs 1 and 2.

It can be seen that within the accuracy of the experiment the absorption edge in the before-threshold area of energies has an exponential form of the type (1). Table 2 tabulates the values $E_{g}$ and $W$ that were used in the calculations. As was expected, the value of parameter $z$ in all the cases was close to unity.

\section{Results and discussion}

The paper [19] reports on the dependence of the energy $W$ on the concentration of active defects in a crystal. It can be seen that even weak doping causes a pronounced additional smearing of the absorption edge. In so doing, a rise in $W$ caused by impurities is the same with singlecharge impurity donors and acceptors, whereas a rise in $W$ caused by introduction to undoped crystal of mercury vacancies that are two-charge acceptors is 3-5-fold. Hence, it follows that a rise in $W$ is almost quadratically dependent on the defect charge, hence it is proportional to matrix component of scattering by impurity ions. In full agreement with formula (2), the introduction, for example, of additional acceptors results in growing absorption through a depletion of conduction band, on the one hand, and a rise in $W$, on the other hand. Analysis shows [19] that taking into account both (and only both) these factors at the same time can explain completely a change in absorption spectra, which can be observed experimentally. In the calculation it was assumed that $z=1.35$. The value $E_{g}$ used in the calculation was determined for each of the samples according to the absorption data obtained prior to doping and was considered independently of acceptor concentration. Hence, the value of fitting parameter $z$ is practically independent of the degree of crystal disordering, whicn makes the model proposed in [19] particularly useful.

Comparison with the results of the paper [15] given in Table 2 shows that modeling the edge of fundamental absorption can help to specify the values $E_{\mathrm{g}}$ found in the regular way from optical measurements, as it was made in Ref. [15]. All the values of the bandgap of crystals under study are in good agreement with the results from [15], the latter being always within the accuracy limits determined by the value $W$.

Table 1. Comparative characteristics of atoms for solid solutions of the type $\mathrm{Hg}_{1-\mathrm{x}-\mathrm{y}} \mathrm{Cd}_{\mathrm{x}} \mathrm{Te}$ [2].

\begin{tabular}{|c|c|c|c|}
\hline Atoms & $\begin{array}{c}\text { Atomic radius, } \\
\mathrm{nm}\end{array}$ & $\begin{array}{c}\text { Ionic radius } E^{2+} \\
\mathrm{nm}\end{array}$ & $\begin{array}{c}\text { Electron } \\
\text { structure }\end{array}$ \\
\hline $\mathrm{Cd}$ & 0.156 & 0.099 & $4 s^{2} 4 p^{6} 4 d^{10} 5 s^{2}$ \\
\hline $\mathrm{Zn}$ & 0.139 & 0.083 & $3 s^{2} 3 p^{6} 3 d^{10} 4 s^{2}$ \\
\hline $\mathrm{Mn}$ & 0.130 & 0.091 & $3 s^{2} 3 p^{6} 3 d^{5} 4 s^{2}$ \\
\hline
\end{tabular}


Table 2. Parameters of samples used for calculations.

\begin{tabular}{|c|c|c|c|c|}
\hline \multicolumn{5}{|c|}{ Ingot 1 (Fig. 1) } \\
\hline $\begin{array}{c}\text { No in } \\
\text { Fig.1 }\end{array}$ & Sample & $E_{\mathrm{g}}, \mathrm{eV}$ & $W, \mathrm{eV}$ & $\begin{array}{c}E_{\mathrm{g}}, \mathrm{eV} \\
{[15]}\end{array}$ \\
\hline 1 & $1 \mathrm{a}-1$ & 0.2898 & $6 \cdot 10^{-3}$ & 0.297 \\
\hline 2 & $1 \mathrm{~b}-10$ & 0.2464 & $7.2 \cdot 10^{-3}$ & 0.244 \\
\hline 3 & $1 \mathrm{~b}-5$ & 0.2365 & $13 \cdot 10^{-3}$ & 0.224 \\
\hline 4 & $1 \mathrm{~b}-2$ & 0.18 & $21 \cdot 10^{-3}$ & 0.157 \\
\hline 5 & $1 \mathrm{a}-4$ & 0.2835 & $15 \cdot 10^{-3}$ & 0.275 \\
\hline 6 & $1 \mathrm{~b}-9$ & 0.2445 & $22 \cdot 10^{-3}$ & 0.235 \\
\hline 7 & $1 \mathrm{~b}-3$ & 0.1933 & $20 \cdot 10^{-3}$ & 0.175 \\
\hline \multicolumn{5}{|c|}{ Ingot 2(Fig. 2$)$} \\
\hline \begin{tabular}{c|c|c|c|c|} 
No in \\
Fig.2
\end{tabular} & Sample & $E_{\mathrm{g}}, \mathrm{eV}$ & $W, \mathrm{eV}$ & $\begin{array}{c}E_{\mathrm{g}}, \mathrm{eV} \\
{[15]}\end{array}$ \\
\hline 1 & $2 \mathrm{~b}-1$ & 0.228 & $40 \cdot 10^{-3}$ & 0.2 \\
\hline 2 & $2 \mathrm{a}-6$ & 0.25 & $75 \cdot 10^{-3}$ & 0.244 \\
\hline 3 & $2 \mathrm{a}-7$ & 0.24 & $90 \cdot 10^{-3}$ & 0.23 \\
\hline 4 & $2 \mathrm{a}-3$ & 0.345 & $15 \cdot 10^{-3}$ & 0.335 \\
\hline
\end{tabular}

Analyzing the data from Table 2 and comparing the first and second ingots, one can conclude that impurity concentration in the second ingot is much greater than that in the first one, since the average value of the energy of spectrum smearing $W$ in the second ingot is higher. This conclusion correlates with the results of the paper [15], where galvanomagnetic studies of the samples used in the present work were performed. It was shown [15] that the concentration of the acceptor impurity in the samples cut out from the second ingot $\left(\sim 10^{17} \mathrm{~cm}^{-3}\right)$, on the average, exceeds the concentration in the samples of the first ingot $\left(\sim 10^{15}-10^{16} \mathrm{~cm}^{-3}\right)$ more than by an order of magnitude.

\section{Conclusions}

1. Based on the model constructed for interband absorption coefficient, the bandgap of $\mathrm{Hg}_{1-\mathrm{x}-\mathrm{y}-\mathrm{z}} \mathrm{Cd}_{\mathrm{x}} \mathrm{Mn}_{\mathrm{y}} \mathrm{Zn}_{\mathrm{z}} \mathrm{Te}$ samples of various compositions and impurity concentrations is calculated.

2. It is shown that using this model specified values of bandgap can be obtained as compared to (1) at $\alpha_{\mathrm{g}}=$ $500 \mathrm{~cm}^{-1}$.

3. Qualitative relationship between the acceptor impurity concentration in the samples and the value of smearing interband absorption spectrum $W$ is established.

\section{References}

1. W. Walukiewicz, Dislocation density reduction by isoelectronic impurities in semiconductors // Appl. Phys. Lett. 20, p. 2009-2011 (1989).

2. A.V. Novoselova, V.B. Lazarev et al., Physics and chemical properties of semiconductor materials. Nauka, Moscow, 1976 (in Russian).

3. R. Grangler, A. Lasbley, S. Rolland et al. // J. Crystal Growth 88, p. 682 (1988).

4. V.A. Rabinovich, Z.Ya. Khavin, Brief chemical handbook. Khimiya, Leningrad, 1978 (in Russian).

5. G.V. Beketov, A.E. Belyayev, S.A. Vitusevich, S.V. Kavertsev, S.M. Komirenko, Peculiarities of transport effects in epitaxial films n$\mathrm{MnHgTe} / \mathrm{CdZnTe} / /$ Fizika $i$ tekhnika poluprovodnikov 31 (3), p. 342-346 (1997) (in Russian).

6. N.N. Berchenko, V.E. Krevs, V.G. Sredin, Semiconductor solid solutions and their application. Voyenizdat, Moscow, 1982 (in Russian).

7. J.K. Furdyna, Electrical, optical and magnetic properties of $\mathrm{Hg}_{1-\mathrm{x}} \mathrm{Mn}_{\mathrm{x}} \mathrm{Te} / / \mathrm{J}$. Vac. Sci. Technol. 21, No 1, p. 220-228 (1982).

8. C. Lewiner, J.A. Gaj, G. Bastard, Indirect exchange interaction in $\mathrm{Hg}_{1-\mathrm{x}} \mathrm{Mn}_{\mathrm{x}}$ Te and $\mathrm{Cd}_{1-\mathrm{x}} \mathrm{Mn}_{\mathrm{x}}$ Te alloys / Proc. Intern. Conf. on Magnetic Semiconductors, Montpellier, 1979. // J. Phys. (France) 41, p. C5289 (1980).

9. S. Nagata, R.R. Galazka, D.P. Mullin et al., Magnetic susceptibility, specific heat, and the spinglass transition in $\mathrm{Hg}_{1-\mathrm{x}} \mathrm{Mn}_{\mathrm{x}} \mathrm{Te} / /$ Phys. Rev. B 22, p. 3344-3355 (1980).

10. N.V. Brandt and V.V. Moshchalkov, Semimagnetic semiconductors // Adv. Phys. 33, p. 193-256 (1984).

11. G.G. Tarasov, Yu.I. Mazur, J.W. Tomm, Peculiarities of interband photoluminescence in the semimagnetic semiconductor $\mathrm{Hg}_{1-\mathrm{x}} \mathrm{Mn}_{\mathrm{x}} \mathrm{Te} / /$ Infrared Phys. Technol. 36, p. 929-936 (1995).

12. G.G. Tarasov, Yu.I. Mazur, J.W. Tomm et al., Optical diagnostics of quaternary narrow-gap semiconductors // Proc. SPIE 2113, p. 17-26 (1994).

13. Yu.I. Mazur, G.G. Tarasov, V. Jashke et al., Excitonic magnetoluminescence enhancement in semimagnetic $\mathrm{Hg}_{1-\mathrm{x}-\mathrm{y}} \mathrm{Cd}_{\mathrm{x}} \mathrm{Mn}_{\mathrm{y}} \mathrm{Te} / /$ Semicond. Sci. Technol. 11, p. 1291-1301 (1996).

14. I.N. Gorbatyuk, A.V. Markov, S.E. Ostapov, I.M. Rarenko, HgCdMnZnTe: a new alternative to HgCdTe // Fizika i tekhnika poluprovodnikov 38, No 12, p. 1414-1418 (2004) (in Russian).

15. I.N. Gorbatyuk, S.E. Ostapov, S.G. Dremlyuzhenko et al., Research on physical properties of $\mathrm{HgCdMnZnTe}$ as a new material in IR optoelectronics// Fizika i tekhnika poluprovodnikov 39, No 9, p. 1053-1058 (2005) (in Russian). 
16. I.N. Gorbatyuk, S.E. Ostapov, V.V. Zhikharevich, Investigation of the physical properties of multicomponent solid solutions $\mathrm{Hg}_{1-\mathrm{x}-\mathrm{y}-\mathrm{z}} \mathrm{A}_{\mathrm{x}} \mathrm{B}_{\mathrm{y}} \mathrm{C}_{\mathrm{z}} \mathrm{Te}$ // Semiconductor Physics, Quantum Electronics and Optoelectronics 8 (1), p.31-36 (2005).

17. M.W. Scott, Energy gap in $\mathrm{Hg}_{1-\mathrm{x}} \mathrm{Cd}_{\mathrm{x}} \mathrm{Te}$ by optical absorption // J. Appl. Phys. 40, No 10, p. 40774081 (1969).
18. V.L. Bonch-Bruyevich, S.G. Kalashnikov, Physics of semiconductors. Nauka, Moscow 1990 (in Russian).

19. V.V. Bogoboyaschiy, The problem of practical determination of optical bandgap in narrow-gap $\mathrm{Hg}_{1-\mathrm{x}} \mathrm{Cd}_{\mathrm{x}} \mathrm{Te}$ crystals // Kondensirovannye sredy $i$ mezhfaznye granitsy 2, No 3, p. 223 - 228 (2000) (in Russian).

20. B. Riedley, Quantum processes in semiconductors. Mir, Moscow, 1986 (in Russian). 